Please do not remove this page

RMIT

UNIVERSITY

\title{
Transafe: A Crowdsourced Mobile Platform for Crime and Safety Perception Management
}

Hamilton, Margaret; Salim, Flora; Cheng, Eva; Choy, Sue Lynn

https://researchrepository.rmit.edu.au/esploro/outputs/9921858507601341/filesAndLinks?institution=61RMIT_INST\&index=null

Hamilton, M., Salim, F., Cheng, E., \& Choy, S. L. (2011). Transafe: A Crowdsourced Mobile Platform for Crime and Safety Perception Management. IEEE International Symposium on Technology and Society 2011, 32-37. https://doi.org/10.1145/2095272.2095275

Document Version: Accepted Manuscript

Published Version: https://doi.org/10.1145/2095272.2095275

Repository homepage: https://researchrepository.rmit.edu.au

(C) 2011 IEEE

Downloaded On 2023/04/26 12:44:56 +1000

Please do not remove this page 
Thank you for downloading this document from the RMIT Research Repository.

The RMIT Research Repository is an open access database showcasing the research outputs of RMIT University researchers.

RMIT Research Repository: http://researchbank.rmit.edu.au/

\section{Citation:}

Hamilton, M, Salim, F, Cheng, E and Choy, S 2011, 'Transafe: A Crowdsourced Mobile Platform for Crime and Safety Perception Management', in IEEE (ed.) IEEE International Symposium on Technology and Society 2011, Chicago, USA, May 23-25, 2011, pp. 32-37.

See this record in the RMIT Research Repository at:

http://researchbank.rmit.edu.au/view/rmit:14549

Version: Accepted Manuscript

Copyright Statement: ( 2011 IEEE

Link to Published Version:

http://dx.doi.org/10.1145/2095272.2095275

\section{PLEASE DO NOT REMOVE THIS PAGE}




\section{Transafe: A Crowdsourced Mobile Platform for Crime and Safety Perception Management}

\author{
M. Hamilton \\ School of Computer \\ Science and IT \\ RMIT University \\ Melbourne, Australia 3000 \\ mh@cs.rmit.edu.au
}

\author{
F. Salim \\ Spatial Information \\ Architecture Laboratory \\ RMIT University \\ Melbourne Australia 3000 \\ flora.salim@rmit.edu.au
}

\author{
E. Cheng \\ School of Electrical and \\ Computer Engineering \\ RMIT University \\ Melbourne, Australia 3000 \\ eva.cheng@rmit.edu.au
}

\author{
S. L. Choy \\ School of Mathematics and \\ Geospatial Sciences \\ RMIT University \\ Melbourne, Australia 3000 \\ suelynn.choy@rmit.edu.au
}

\begin{abstract}
This paper describes a proposed mobile platform, Transafe, that captures and analyses public perceptions of safety to deliver 'crowdsourced' collective intelligence about places in the City of Melbourne, Australia, and their affective states at various times of the day. Public perceptions of crime on public transport in Melbourne are often mismatched with actual crime statistics and such perceptions thus can act as social barriers to visitors and locals traversing within and through the city. Using interactive mobile applications and social media, the visualization of this crowdsourced safety perception information will increase the commuter's awareness of various situations in the City of Melbourne. In addition, through social behavioral analysis and ethnographic research, the collective public intelligence will also help inform the stakeholders of the city for future policy-making and policing strategies for safety perception management. At the centre of the proposed platform is the design and development of a mobile phone application that can contribute to people feeling safer by supporting users to report crimes and misdemeanors that they witness, and provide information about transportation and emergency services around where the users are located. The proposed application can also act as a crime deterrent with one feature that enables user tracking by up to three nominated friends if the user opts to activate tracking when feeling unsafe while roaming the city.
\end{abstract}

Keywords-crowdsourcing; mobile application; safety perception; crime perception

\section{INTRODUCTION}

The mass media have a great influence on public perceptions of safety: for example, in the City of Melbourne in Victoria, Australia, local media sources often report that a high percentage of commuters feel unsafe and vulnerable, particularly while travelling on public transportation networks [1][2][3]. In actuality, however, Melbourne has a very safe transport system and the level of crime occurring on Melbourne's transportation networks is dropping: in 2005-06, 45 offences per million train passengers were reported, compared to 33 per million passengers in 2008-09, where 75\% of public transport offences in the City of Melbourne occur on trains, train stations and station car parks [4]. In contrast, the safety perception scores on Melbourne's trains are significantly lower than for trams and buses, and have not improved over the last five years despite a statistical decrease in the number of offences occurring per passenger [4].

The perception of safety is important as it influences how people feel and behave towards their surroundings; however, perceptions of safety do not solely depend on levels of crime [4]. Thus, the perception of high levels of crime on Melbourne's public transport can potentially introduce social barriers experienced by (tourist) visitors to Melbourne, international students, and locals who feel unsafe on public transport. Understanding public perceptions of safety and developing policies and strategies to alleviate negative perceptions of crime and safety in the City of Melbourne have become key agendas of Melbourne City Council [5] and Victorian State Government [6]. Currently, Victoria Police operates a Transit Safety Division whilst Crime Stoppers, an independent organization that allows for the public to report criminal activity and suspicious behavior to police, operates a Public Transport program. Hence, the main research question in the Transafe project is:

How can information regarding public perception on crime be used to promote and facilitate feelings of safety within the city?

This paper describes the concept and proposed development of a platform called Transafe that combines interactive mobile applications with social media to capture and analyze public perceptions of safety and deliver 'crowdsourced' collective intelligence about places in the City of Melbourne with their affective states at various times of the day. The recent rise of social media sites e.g., micro-blogging, social networking, and Web 2.0 applications powered with geo-tagging capabilities, when accessed from mobile devices, provide networks of emergence and convergence of spatial interactions and knowledge of and about our cities [7]. There is great potential to capture new information through 'crowdsourcing', which outsources the tasks of developing new technology or applications to the crowd through an open call [10].

When mobile phone applications enable crowdsourced content to be submitted, the applications self-evolve over time where developers only need to create an intuitive placeholder for the crowdsourced content. Crowd place-making is spatial movement of the crowd that is voluntarily reported via mobile applications that can track locations using GPS and geo-tagging 


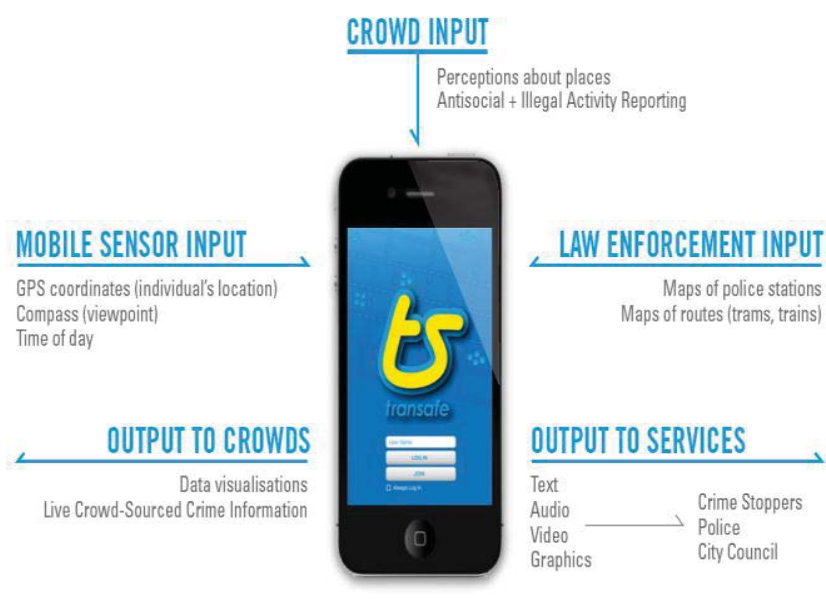

Figure 1. Proposed Transafe platform (and interface mockup)

and accepts rich user inputs about whereabouts [7]. Existing popular crowd place-making applications such as 'Facebook Places ${ }^{1}$ or 'Foursquare ${ }^{2}$ have become very popular; however, these sites do not integrate contextual information from public service infrastructure and emergency services and are not designed for understanding public perceptions or performing specific social interventions.

Further, crowdsourcing does not rely on data provision; rather, it relies entirely on the crowds to provide the data as long as the crowds can find benefit and engagement from the activity they are involved in. This is particularly demonstrated by crowd democracy activities, which could be part of crowd voting through the online platforms used solely to gather and present a community voice to local, state, or federal governments. An example of this is 'Fix My Street', ${ }^{3}$ a site to report, view, or discuss local problems (such as graffiti, broken road surface, pothole, or street lighting). At the time of writing, there had been 879 reports in the past week, 87,868 updates on reports, and 2,104 reported problems fixed in the past month. The data reported on such applications can thus be used to analyze emerging patterns on the use of infrastructure and mobility of users of the city [7].

In an effort to address crime through technology, in Australia, an iPhone application has been developed to directly connect users to report suspicious or criminal activity with multimedia to Crime Stoppers'. Similarly, the '311' initiative introduced in 2008 in New York allows users to send multimedia reports of anti-social behavior from their mobile phone or computer to the NYPD's Real Time Crime Center (an extension of the text messaging reporting service to Crime Stoppers already in place). Specifically addressing public transport crime, the 'See Something Say Something' initiative launched in September 2010 in Walsall (British West Midlands) encourages bus passengers to text in suspicious behavior through an anonymous SMS. However, whilst

\footnotetext{
${ }^{1}$ http://www.facebook.com/places/

2 http://foursquare.com/

3 http://www.fixmystreet.com/

${ }^{4}$ http://stopcrime.chrisvanraay.com/
}

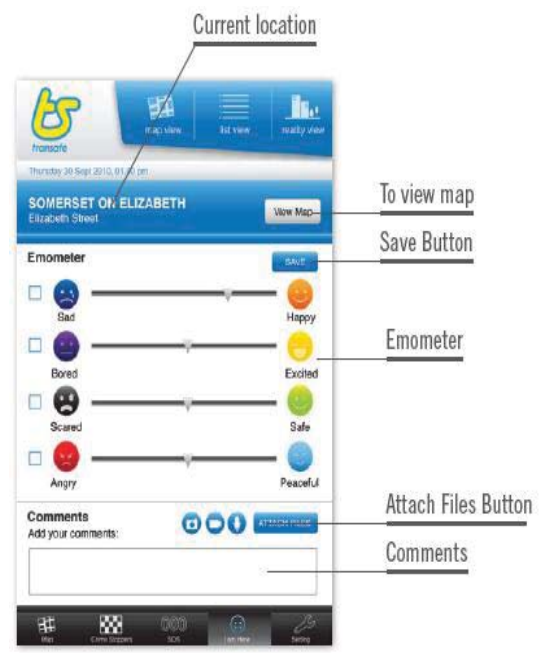

Figure 2. Emometer interface mockup

effective, such initiatives are unidirectional reporting mechanisms that do not address the disparity in public safety perception and actual criminal offence activity. Thus, Transafe aims to draw together interactive mobile technology, crowdsourcing, crowd place-making and the provision of contextual information about location-aware aggregated public safety perceptions, public services and transport options to help address and study the disparity between safety perceptions and actual criminal offences on Melbourne public transport.

In the remainder of this paper, Section II describes the proposed Transafe platform and mobile phone application. Section III presents example user scenarios and use-cases of the platform, whilst Section IV details the current status and progress of the project. Section V concludes this paper.

\section{Proposed TRANSAFe PlatForm}

Figure 1 illustrates the proposed platform for Transafe, centered around a mobile phone application that allows for:

- Direct user interaction: users interact with the application to submit and view crowdsourced crime and safety perception data. Mobile phone sensors will be used as input for user place-marking, timestamps etc.

- Stakeholder interaction: organizations such as city councils, public transport entities, and state government bodies can input infrastructure or (real-time) transport information and law enforcement agencies such as Police and Crime Stoppers can provide crime news and information;

- User services: improving personal safety perceptions through enabling a user tracking system, or connection to civil services such as emergency calls ('000') or criminal/suspicious activity reporting to Crime Stoppers. 


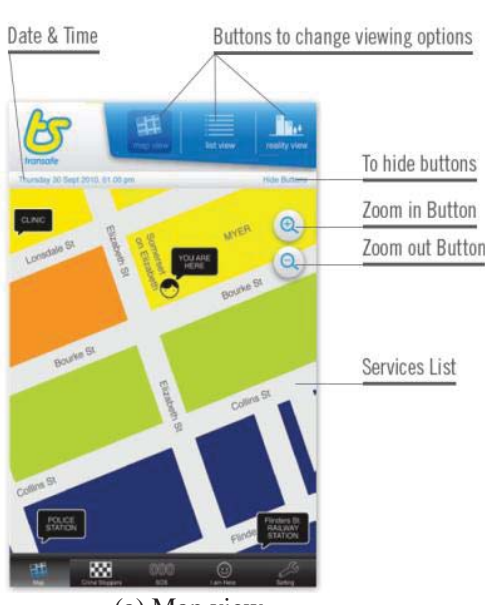

(a) Map view

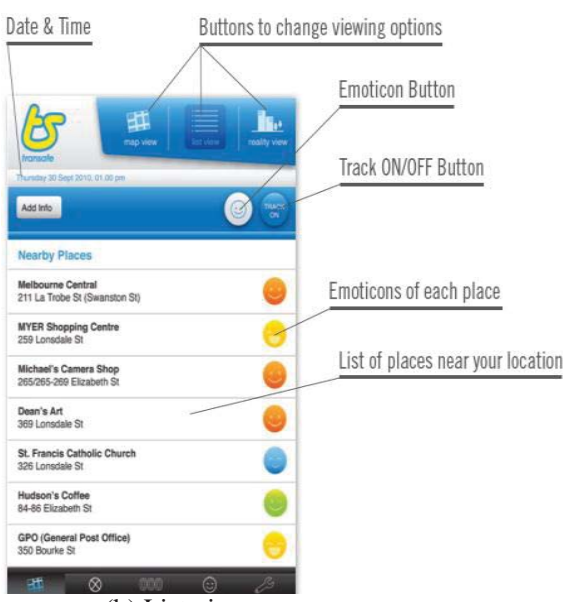

(b) List view

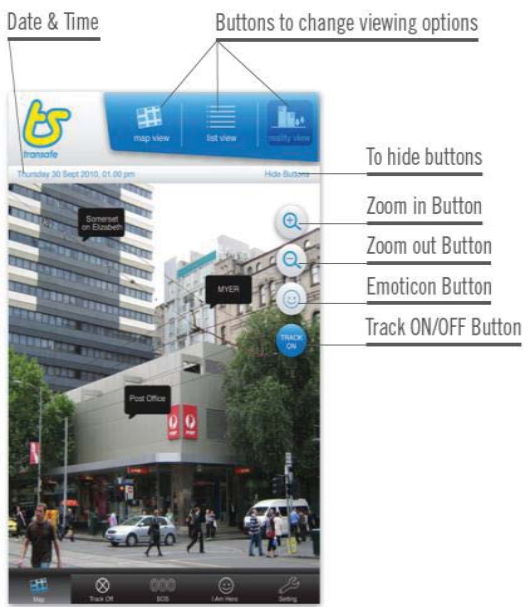

(c) Reality view

Figure 3. Multiple map view interface mockup

\section{A. Direct user interaction}

Transafe introduces the use of an 'emometer', a crowd voting mechanism with emoticons to encourage people to explain their feelings or perceptions of a particular place at any given time. These emoticons have ranges of intensity and so the user can provide an intricate color display of perceptions. A user can enter information about their perceptions of a particular area by selecting one or all of the 8 emoticons with different colors representing Sad/Happy, Bored/Excited, Scared/Safe, Angry/Peaceful sliding scales (see Figure 2).

The submitted Emometer data is then aggregated across the user crowd and the result will determine the overall color/mood of a particular area/locale. Visualizing the 'feelings' of places in the city on different 'map', 'list' and 'reality' viewing modes then allows for the user to see collective safety perceptions of places at different granularity (see Figure 3): Figure 3a illustrates the 'map' view augmented with the crowd's 'mood' for each city block; Figure 3b shows the 'list' view of the crowd's mood for particular buildings and landmarks; and, Figure $3 \mathrm{c}$ depicts the 'reality' map indicating nearby buildings and facilities.

\section{B. Stakeholder interaction}

Transafe gives the user the option to choose information about the nearest public civil infrastructure such as public transport, hospitals and police stations. Particularly when the user is unfamiliar with the city or their immediate locale, knowledge about nearby accessible public services can aid to alleviate feelings of anxiety about personal safety.

In addition, real-time newsfeeds will also inform the user of recent criminal activity within the area (utilizing the Crime Stoppers newsfeed) as well as transport information about the nearest train stations, tram stops, bus stops and taxi services. Real-time train, tram and bus schedules can also be enabled, utilizing services such as the Tram TRACKER application ${ }^{5}$.

\footnotetext{
${ }^{5}$ http://tramtracker.yarratrams.com.au/
}

\section{User Services}

Transafe provides users with an 'SOS' button for the option of calling ' 000 ' in case of emergencies for fire / ambulance / police response. This feature sits on the menubar at the bottom of the user interface, so the user can easily click on it and directly ring '000' for emergency services.

To report potential criminal activity or evidence to Crime Stoppers, photos, voice notes, or video options can be selected from the user's multimedia library or taken on the spot with the built-in phone camera/microphone. By pressing the send button, the information will be (anonymously) submitted to Crime Stoppers to be stored in Crime Stoppers database, building upon technology such as the Crime Stoppers iPhone application $^{4}$.

Transafe also supports a user tracking system through the use of the in-built GPS receiver. This feature will be extremely useful for tracking a user who is in an unsafe environment. The user can nominate three trustable family members, relatives or friends (trustable members) who also have the Transafe application installed on their mobile phones. How this system works is that once the user activates the tracking system, the three trustable members will receive a notification on their mobile phones informing them that he/she is feeling vulnerable and unsafe. His/her positions will be transmitted constantly through the network and the three can track the position of the user, their friend or family member, on the Transafe map. If required, they can then act or seek help since they know exactly where he/she is.

\section{EXAMPLE USER SCENARIOS}

Transafe's features described in Section II aim to help people feel safer and support them as they travel across and within the City of Melbourne. In addition to assisting visitors and locals alike, the (anonymous) collected data can be utilized to study perceptions of safety and crime for city stakeholders as well as researchers for further analysis. The following usecases are some anticipated examples of how Transafe might be 


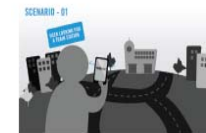

User tries to find the nearest Transafe identifies nearest public transport

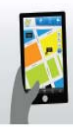

public transport
Figure 4. Public transport use case

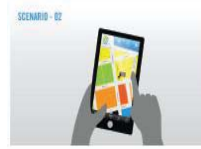

User presses emoticon button User selects emometer to input perception data

Figure 5. Emometer use case

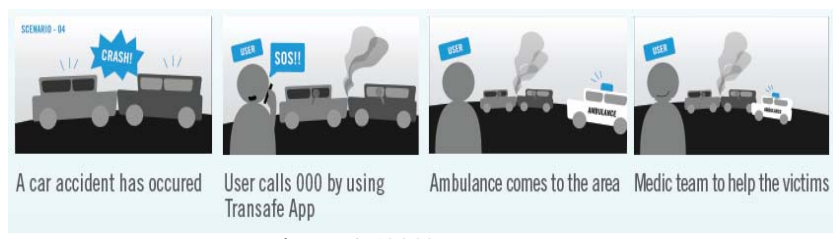

Figure 6. '000' call use case

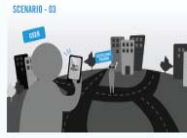

User takes picture of a suspicious person

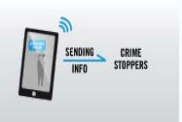

User sends the info to Crime Stoppers

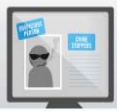

Data of Suspicious Person has The data of Suspicious Person been sent to Crime Stoppers is now on Crime Stoppers database

Figure 7. Crime Stoppers use case

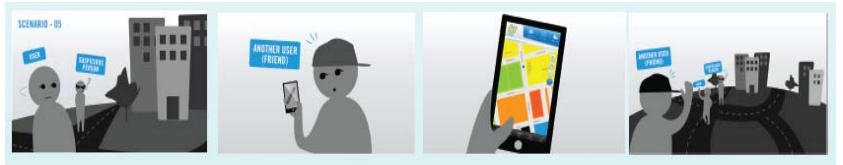

User 1 feels like he's being User 2 receives a notification Now User 2 can see where User 2 comes to meet User 1 followed by a suspicious person from Transafe on his iPhone User 1 is

Figure 8. Tracking system use case

employed; these use cases are also available animated online at http://www.youtube.com/watch?v=4OcdZ0JtRhc.

\section{A. Public transport use case}

With the aid of GPS and AGPS (Assisted-GPS), Transafe can pinpoint the user's position on the 'map' or 'reality' viewing modes, identifying their current location with respect to the surrounding environment. The Transafe map displays street addresses as well as building names. It could also highlight and provide direction to the nearest train station, tram and bus stops (see Figure 4). It serves as a useful navigation tool for tourists to navigate around in the City of Melbourne, in particular, to access the Victorian transport system. In addition, Transafe can identify and provide directions to the nearest Police station if a user were feeling unsafe and needed further information or advice or wanted to report a crime.

\section{B. Emometer use case}

One of the key features of Transafe is the implementation of an 'Emometer' (see Figures 2 and 5). The idea behind the design of the Emometer is to provide users with a tool to express their perceptions of crime and safety at a particular venue at a given time based on their feeling. This crowdsourced information, together with the positions of the users, will be submitted to and stored in the Transafe database for data mining analysis and aggregation. It is also anticipated that this information would be valuable in understanding the public perception of crime and safety in a particular area, i.e., the City of Melbourne, at various times of day.

\section{Emergency services use case}

The dialing of 000 for emergency fire/police/ambulance assistance currently requires the person ringing to speak and identify themselves (Figure 6). If they are witnessing a crime and wish to be anonymous, they will be able to take a photo, sound recording, or video, and submit this to Crime Stoppers (Figure 7). Transafe thus allows users the freedom to choose how to provide information, keeping in mind that ' 000 ' should always be used for life-threatening or time-critical emergencies.

\section{User tracking use case}

Dialling 000 requires a person to speak to the operator and identify themselves. Should the user feel too unsafe or unsure to make an emergency call, they may choose to turn on their user tracking feature (Figure 8). Once user tracking is enabled, the GPS receiver in the phone will be activated and the Transafe application automatically sends a text message with the user's corresponding coordinates to the three nominated family members, relatives or friends. This notification will alert the three trustable members that this person is feeling unsafe and the three trustable members can track their location on the Transafe maps. The intention of this tracking feature is to secretly and silently alert the three members that the user is feeling unsafe. Thus, the position of the user will be made known and their trustable members can act upon it if required, taking into account the time of day, actual location and expected movements of their friend.

\section{FUTURE WORK}

Developing the proposed Transafe mobile phone application on iPhone and Google Android platforms are the immediate next steps in the project. Human-computer interactions, data collection efficiency, and user testing evaluation must also be further studied to enhance the interface design of the application and increase crowd participation in using and evaluating and contributing to the Transafe database.

\section{A. User interface design and testing}

Affective interface design and visualizations require further investigation as whilst we recognize that some people may feel unsafe, others may feel safe and the same people may feel differently at different times of the day, in the same places in the city for different reasons. Hence, the color coding of perceptions of safety in the city will need to be informed by cognitive psychology and a contextual understanding of the data already entered into Transafe database to derive an overall color for a particular position in the city at that time. Further, 
local law enforcement agencies have unique knowledge about the various areas in the city and a good understanding of the impact of publicizing specific information; thus, their experience in identifying what information should be kept private and what can and should be made public have already freely been offered and will be called upon.

Once the Transafe application has been developed, we will need to extensively test it on a variety of users. Firstly, as discussed above, we will need to understand the effects of the color-coded perceptions on users, but secondly, we will need to enable recognition of the individual user contributions through the emoticons and uploading of information. There have been many studies undertaken to interpret feelings through color, such as the research performed by Matei et al [9] who among other questions ask whether comfort and fear are color-coded, and via statistical methods show that perceptions of fear can be associated with crime and can be color-coded. We need to explore the effective ways to influence users to submit information to Transafe and hence build up the collective intelligence about the city. Transafe needs to be designed to encourage users to keep the application running and submit information to the Transafe crowdsourced database. However, as the number of user increases, we do not want to encourage unnecessary or duplicated information to saturate the database. Thus, we recognize the need to add computational intelligence and filtering to regularly moderate the material which is to be kept and acted upon.

\section{B. Data collection efficiency}

When crowdsourcing is combined with computational data mining, there is great potential to discover patterns of public sentiments about places in the City of Melbourne. To increase our understanding of the recurring socio-economic behavioral patterns with crime perception, the massive pool of collected crowdsourced data needs to be analyzed. Recurring patterns that appear in the data may lead to novel and useful information to city stakeholders, and computational data analysis techniques are needed to discover such patterns [9]. Data mining and/or knowledge discovery, which interconnect disciplines from machine learning, statistics, and databases, offer various techniques for data analysis, such as pattern discovery, clustering, classification, and time series analysis which can be applied to our data. Pattern discovery in data mining exists in many forms, from the traditional association rules, to negative association rules and exception rules [7]. When data mining techniques are applied to crowdsourced data on social networks, we can therefore analyze public sentiments over specific matters: this is termed as sentiment mining $[13,14]$

In the Transafe platform and mobile phone application proposed in this paper, crowdsourced social network data can be clustered and labeled to discover patterns of public sentiments over a specific place in the City of Melbourne at different times of the day. Finding recurring patterns and monitoring emergence and changes of the sentiment patterns can inform us of specific activities, events, time, or places that affect public perception of safety. By applying association rules mining, we can thus discover public perception trends in relation to various factors and user groups of the city, in much the same way as Arvidsson describes in his book [8]. Such information can then be streamed back to the public or stakeholders of the city and better inform city planning $[10,11,12,15]$.

\section{Transafe technology platform evaluation}

Finally, whilst the importance of safety and good communication is recognized, measuring the impact of technology to increase public safety perception is a challenge. Evaluating the impact of Transafe on influencing public perception of safety in the city requires a further study after the application is marketed and used for at least six months. Ethnographic surveys and observations must also be conducted to understand the effects of social computing and mobile applications in changing public sentiments.

There is much work currently being undertaken in this field, such as the work of the Cyberemotions Consortium headed by Professor Holyst [16] investigating the role of ICTmediated social interactions in e-communities which began in February 2009 funded to continue in Europe for four years, and the MIT Media Lab project [17] which is using mobile phone data to infer behavioural data of friendships. In Transafe, we will use the data collected from mobile phones to infer social behaviour and public perception about crime and safety. Also, it is interesting to note that Google has recently purchased a sentiment analysis tool [18] to incorporate in its search engine.

\section{CONCLUSION}

Public perceptions of safety and crime on public transport are often significantly disparate to actual crime statistics in the City of Melbourne in Victoria, Australia. A recent study on the safety perceptions for young people travelling on public transport in Melbourne, highlighted the anxiety experienced by young women in particular, and concluded that:

"Research needs to explore factors influencing psychological perceptions such that information and design measures might be used to positively influence these perceptions."[19].

Such perceptual disparities can lead to potential social barriers for (tourist) visitors, international students and locals travelling within and around the city: criminal offences have actually decreased on Melbourne public transport in recent years yet public perceptions of safety have either worsened or not changed.

This paper proposed and described the concept and development of an interactive mobile phone platform, Transafe, which combines crowdsourced safety perceptions with crowd place-making and the provision of contextual information about nearby public services and transport options to help address and study the disparity between public safety perceptions and actual criminal activity on Melbourne public transport. The collected data not only benefits the application users but can also be analyzed for social behavioral or ethnographical studies on public safety perceptions and help to inform the stakeholders of the city for future policy-making and policing strategies for safety perception management. 


\section{REFERENCES}

[1] Herald Sun, "Government says rail crime rate dropping as violence hotspots revealed", 28 June 2010.

Available online: http://www.heraldsun.com.au/news/victoria/citysmost-dangerous-stations/story-e6frf7kx-1225884963316

[2] The Age, "Tram violence taskforce dissolved," 9 June 2010.

Available online: http://www.theage.com.au/victoria/tram-violencetaskforce-dissolved-20100608-xtog.html

[3] The Age, "It's a war zone, say Melbourne's train drivers," 12 June 2010.

Available online: http://www.theage.com.au/victoria/its-a-war-zone-saymelbournes-train-drivers-20100611-y3o7.html

[4] Victorian Auditor General, "Victorian Auditor General's Report: Personal Safety and Security on the Metropolitan Train System," June 2010.

Available online:

http://download.audit.vic.gov.au/files/20100609_Rail_Safety_Full_Repo rt.pdf

[5] City of Melbourne, "City of Melbourne's Policy for the 24 Hour City, A framework for action," April 2010.

Available online:

http://www.melbourne.vic.gov.au/CommunityServices/CommunitySafet y/Documents/24\%20Hour\%20City\%20Policy.pdf

[6] Victorian State Government (Department of Premier and Cabinet), "Growing Victoria Together, A Vision for Victoria to 2010 and Beyond," March 2005.

Available online:

http://www.dse.vic.gov.au/CA256F310024B628/0/F0545EFAF0609F09 CA256FD400002FD0/\$File/GVT.pdf

[7] Salim, F., Burry, J., Taniar, D., Lee, V.C., Burrow, A. "The Digital Emerging and Converging Bits of Urbanism," in proc. eCAADe 28th conference - Future Cities, Zurich, Switzerland, 15-18 September 2010.

[8] Arvidsson, A., "Brands: Meaning and value in media culture", Routledge, Taylor and Francis Group, N.Y., ISBN 10:0-415-34715-7, 2006.

[9] Matei, S., Ball-Rokeach, S. J., Qiu, J. L., "Fear and Misperception of Los Angeles Urban Space A Spatial-Statistical Study of Communication-Shaped Mental Maps", Communication Research, 28(4), August 2001, p429-463.

Available online:

http://mentalmap.org/files/matei_fear_CR.pdf.
[10] Brabham, D.C., "Crowd Sourcing as a Model for Problem Solving: An Introduction and Cases", Convergence: International Journal of Research into New Media Technologies, February 2008, 14(1), p76-90.

Available online: http://con.sagepub.com/content/14/1/75.short.

[11] Brabham, D.C., "Crowd Sourcing the Public Participation Process for Planning Projects", Planning Theory August 2009 vol. 8 no. 3 242-262.

[12] Brighenti, A. M., "New Media and the Prolongations of Urban Environments", Convergence: The International Journal of Research into New Media Technologies, November 2010; vol. 16, 4: pp. 471-487.

[13] Pang, B., Lee, L., "Opinion Mining and Sentiment Analysis", Foundations and Trends in Information Retrieval, 2(1-2), January 2008. Available online: http://portal.acm.org/citation.cfm?id=1454712.

[14] Maio, Q., Li, Q., Dao, R., "AMAZING: A sentiment mining and retrieval system", Expert Systems with Applications 36 (3), April 2009, p7192-7198.

[15] Howe, J., Crowdsourcing: Why the Power of the Crowd is Driving the Future of Business, 1st ed., Crown Publishing Group, NY, USA, 2008.

[16] Holyst, J., The Cyber Emotions Project, "Collective Emotions in CyberSpace", funded by they European Union, Feb 3, 2009.

Available online: http://www.cyberemotions.eu/index.html

[17] Eagle, N., Pentland, A., and Lazer, D., "Inferring Social Network Structure using Mobile Phone Data", Proceedings of the National Academy of Sciences (PNAS), 2009, 106(36), pp. 15274-15278.

Available online: http://reality.media.mit.edu/pdfs/Eagle_PNAS09.pdf.

[18] Moran, M., “ How is Google feeling about Sentiment Analysis?”, Search Engine Guide, www.searchengineguide.com, February 3, 2011.

Available online:

http://www.searchengineguide.com/mike-moran/how-is-google-feelingabout-sentiment-an.php

[19] Currie, G., Delbosc, A., Mahmoud, S., "Perceptions and Realities of Personal Safety on Public Transport for Young People in Melbourne", 23rd Australasian Transport Research Forum, Canberra Sept 29th October 1st 2010.

Available online:

http://www.patrec.org/web_docs/atrf/papers/2010/1902_048\%20\%20Currie\%20Delbosc\%20Mahmoud.pdf. 